$$
\text { Lexis Vol. XLII (2) 2018: 473-502 }
$$

\title{
Una crónica alternativa de la conquista de México. Otra Historia verdadera de la conquista de la Nueva España
}

\author{
Rubén D. Medina \\ Universidad Nacional Autónoma de México
}

\section{RESUMEN}

La Historia verdadera de la conquista de la Nueva España por el capitán Fernando Cortés es un manuscrito de 382 folios, recto y verso (signatura MSS/2997 de la Biblioteca Nacional de España), de la autoría de Pedro Fernández de Pulgar (1621-1697). Reconstruye los acontecimientos de la ocupación militar de los territorios maya, tlaxcalteca y azteca por parte de las tropas comandadas por Hernán Cortés, hasta la capitulación de la ciudad de México Tenochtitlán. Basada en historias previas, esta versión realiza un balance histórico e intenta abatir la "leyenda negra", cuyo origen atribuye a fray Bartolomé de las Casas.

Palabras clave: crónica, manuscrito, retórica, edición

\section{AbSTRACT}

The True story of New Spain conquest by captain Fernando Cortés is a manuscript with 382 sheets (classification MSS/2997 in the Spain National Library). The author is Pedro Fernández de Pulgar (1621-1697). The facts of the military occupation of the Mayan, Tlaxcaltecan and Aztec territories, by the Cortes's troops, are reconstructed in this book, until Mexico

https://doi.org/10.18800/lexis.201802.007 
Tenochtitlan downfall. Based on previous stories, the perspective of this writing is to tear down the "black legend", supposedly created by father Bartolomé de las Casas.

Keywords: chronicle, manuscript, rhetoric, edition

\section{Introducción}

El presente artículo se propone ofrecer los primeros pormenores de un material manuscrito que se encuentra en la Biblioteca Nacional de España: la Historia verdadera de la conquista de la Nueva España por Fernando Cortés, elaborado por Pedro Fernández de Pulgar. Tras una dilatada labor, el texto se encuentra en preparación para ser publicado. Las palabras que siguen intentan hacer una semblanza sucinta del contenido de la obra y de algunas de sus estrategias discursivas.

\section{El texto y el paradigma}

En la nutrida bibliografía sobre la conquista de México, los escritores españoles del siglo XVII contribuyen con dos trabajos destacables: Antonio de Solís (Alcalá de Henares, 1610 - Madrid, 1686) con su Historia de la conquista de Méjico, y Pedro Fernández de Pulgar (Medina de Rioseco, 1621 - Madrid, 1697) con la crónica que da pie a las presentes líneas. Con el título que escoge para su escrito, Historia verdadera de la conquista de la Nueva España (en adelante, Historia verdadera $)^{1}$, Fernández de Pulgar hace evidente su visión de la historia. Actitud temeraria, sin duda, pero Fernández de Pulgar asume la verdad por sobre las historias de primera mano como la de Hernán Cortés y la de Bernal Díaz del Castillo. Deja claras, además,

\footnotetext{
1 Pedro Fernández de Pulgar, Historia verdadera de la conquista de la Nueva España. S/l, s/a. BNE mss/2997. La clasificación de la biblioteca la presenta como "Conquista de la Nueva España por Fernando Cortés”; sin embargo, me parece clara la intención del autor - explícita en el folio 1r, que se constituye como portada del trabajo puesto que en él se consignan título íntegro y dedicatoria- de llamarle Historia verdadera.
} 
las dianas hacia las que dirige los dardos de su verdad: la primera, el escrito del viejo soldado castellano, con respecto al cual manotea el título, lo expropia y lo subraya (la que presenta, desde la perspectiva de su hacedor, equivale a una versión corregida y aumentada de la veracidad). El otro blanco al que apunta, y que acaso le interesa corregir con más vehemencia, es la mencionada Historia de Solís. Sucesor inmediato de este en el cargo de cronista mayor de Indias (desde 1686 hasta el final de sus días), Fernández de Pulgar desliza, por aquí y por allá en su Historia verdadera, críticas contra la reconstrucción de la conquista escrita por Solís. Los motivos de tal acrimonia parecen delatarse solos; al menos, en parte. Heredar el nombramiento obliga al heredero a mejorar la hacienda. Y la figura de Antonio de Solís era, en sus días, muy ilustre. Prosista reconocido, historiador que se atreve con el pasaje de la conquista de México en forma mesurada y, en lo posible, objetiva, dramaturgo amigo y colaborador de Pedro Calderón de la Barca (con quien traduce El pastor de Fido de Giovanni Guarini) y aun poeta conocedor del oficio, ${ }^{2}$ representaba un desafío de mucho peso para su sucesor. Aunque se defiende Fernández con denuedo, como prosista y como historiador parecería perder el combate. La prosa de Solís es mucho

\footnotetext{
2 Prefiere el tema religioso por formación y por moda. En este soneto puede advertirse su aprendizaje de la muchedumbre de poetas religiosos españoles e hispanoamericanos del tiempo. Pero puede observarse también una huella personal, por ejemplo, en la búsqueda de rimas no convencionales como las que se construían, incontables, con inflexiones verbales: “¿Hasta cuándo mi torpe desvario / abusará, Señor, de tu clemencia? / Que parece que aprendo en tu paciencia / más libertad que diste a mi albedrío. // Juzga, corrige, enmienda el error mio / antes que se pronuncie la sentencia. / No llegue, en mi postrera negligencia, / la primera señal de tu desvío. // Tú me diste tu imagen: mi pecado / la borró. Mas, jah, triste! no perezca / tu retrato en mi ciega destemplanza: // vuelva a imprimir tu sangre lo borrado / y, para que la imagen permanezca, / defiéndame de mi tu semejanza" (Solís $1843 \mathrm{XXII).} \mathrm{Este} \mathrm{otro} \mathrm{soneto} \mathrm{igualmente} \mathrm{da} \mathrm{testimonio} \mathrm{de} \mathrm{sus}$ buenas maneras de poeta: "El curso de los años repetido / gasta la edad con natural violencia, / y el tardo amanecer de la prudencia / conoce el tiempo cuando le ha perdido. // La mitad fue del sueño y del olvido, / la otra mitad, o error o negligencia; / mas, ;oh vivir!, dificultosa ciencia, / ¿quién en toda una vida te ha sabido? // Duran los días, ¿pero quién percibe / su duración, si es menos inconstante / la intrepidez de nuestra fantasía? // ¿O qué importa el durar, si solo vive / el que sabe acertar aquel instante, / principio y siempre del eterno día?” (Blecua 1984: 365).
} 
más cuidada y rica, y su visión histórica más panorámica, más generosa y más informada. Bastarían unas cuantas citas (que el espacio de esta disquisición no permite): por ejemplo, del pasaje de la matanza de Cholula narrada por ambos cronistas, para advertir esas diferencias (Solís [1684] 1970: 166-167; Fernández: 165v-166v). ${ }^{3}$

Pero no es Antonio de Solís el único objetivo de la crítica de Fernández. A este lo acusa a veces de omisiones o de ligerezas - "digo que no sé cómo compone Solís el dar título a esta acción de resolverse a prender a Motezuma de resolución heroica” (190v)... “pasó don Antonio Solís los límites de su profesión, y así erró enormemente" $(199 \mathrm{v})$ - , de permitir que los lectores interpreten a su leal entender la historia, _ “ni la civil ni la sagrada deben ser interpretadas libremente”, parecería decir con índice inflexible de dómine severo-, de timorato en asuntos de doctrina - " por todo lo cual, pues, Solís deja al juicio del que leyere este punto... y repruebo el [punto de vista] de Solís, que dice que no halla razón de congruencia política o cristiana para que se perdonasen tantos inconvenientes" (200r-200v) —, y de limitado — “si hubiera ponderado Solís con verdadera inteligencia este suceso, le hallara muy creíble” (200v)—. Su censura, en ocasiones invectiva, como puede verse, se enfoca en varios escritores a quienes denuesta por una supuesta falta de mesura, que tasa en función de su visión particular de la historia y de los vectores políticos que operaban en su tiempo.

Por ese motivo, también Bernal Díaz del Castillo ocupa su atención y recibe reproches. No puede restarle méritos como soldado: su historia como participante en las tres expediciones oficiales al territorio continental desde Cuba no admiten regateo, y, de manera muy subrayada, su aceptación sumisa del papel de peón leal en los tableros bélico y político bajo las órdenes de Hernán Cortés le resultan cualidades de muy crecido valor. Defensor de la idea de algo así como un destino providencial, según puede colegirse con frecuencia de su escrito y según declaración explícita, la asunción

3 En adelante, cito la Historia verdadera de Fernández de Pulgar solo por folios; en este caso, por ejemplo, $165 \mathrm{v}-166 \mathrm{v}$. 
del papel que la suerte asigna a cada quien constituye una de las más altas virtudes del ser humano. A los capitanes toca mandar y a los soldados, obedecer; a los reyes, gobernar; y a los vasallos, acatar, según esa lógica, tal como pontifican estas palabras: "Nacen los súbditos para obedecer y no especular los decretos de los superiores" $(14 \mathrm{v})$. Como soldado, entonces, como pieza del ajedrez bélico ("peón ladino" diría Borges) el desempeño de Bernal no le merece recriminación a Fernández; no le dedica los elogios que parecerían innegables, puesto que todos los dirige al capitán Cortés, pero al menos nada le echa en cara. Ya con respecto a la Historia de Bernal la historia es otra. Le concede el valor de un testimonio... limitado; y, más o menos, la dirección de su voluntad al esclarecimiento de la verdad, no sin bemoles: "Conque parece que por asegurar la verdad escribió Bernal Díaz del Castillo, como conquistador y cuasi testigo de vista. Pero no está libre de censura, como luego se verá" (12r). Pese a ello, una lectura ligera del libro del soldado castellano ${ }^{4}$ es suficiente para percibir la fuerza narrativa del protagonista y para advertir su cautela con respecto a la presentación de la verdad histórica. La repetición de expresiones equivalentes a "yo no lo vi", "no me consta" prueban tal cuidado. Y lo prueban más aún las enmiendas que el propio Bernal realizó de una versión a la otra de su escrito, como en este pasaje:

Otra cosa dijo el Pedro de Alvarado, y esta sola cosa la dijeron otros soldados, que las demás pláticas solo el Pedro de Alvarado lo contaba, y es que no tenían agua para beber, y cavaron en el patio e hicieron un pozo y sacaron agua dulce, siendo todo salado también; todo fue muchos bienes que Nuestro Señor Dios nos hacía. E a esto del agua digo yo que en México estaba una fuente que muchas veces, e todas las más, manaba e tenía agua algo dulce. Estas cosas y otras sé decir, que lo oí a personas de fe y creer que se hallaron con el Pedro de Alvarado cuando aquello pasó.

\footnotetext{
Dejo de lado la hipótesis de Duverger (2015), quien propone que la autoría de la Historia verdadera de la conquista de la Nueva España no es de Díaz del Castillo sino de Hernán Cortés. Me parece insostenible.
} 
Nota 8. Alvarado se justifica señalando posibles prodigios o revelaciones divinas que confirmasen que actuaron correctamente en la matanza del templo... El propio Bernal incluía en el texto primitivo una referencia a la intervención maravillosa de la Virgen María y del apóstol Santiago, que luego tachó; también eliminó la referencia (difundida supuestamente por el padre Las Casas) a la codicia de Alvarado; ambas tachaduras, obviamente, figuran en la edición impresa (Serés, 2011: 462 n.).

Bernal se cuida mucho de afirmaciones indemostrables a la luz de la historia, y su cuidado se acentúa cuando los hechos que menciona atañen a pasajes coyunturales para la apreciación de las decisiones que tomaban los responsables y que determinaron el derrotero de la conquista, además, desde luego, de las expresiones tocantes a la doctrina cristiana. Creyente de buena fe, en su escrito trasparece el respeto sincero a las figuras ideológicas y emblemáticas del catolicismo. Muy probable es, en cambio, que en cuestiones de menor monta se haya explayado, acaso de más, y hasta haya llegado a inventar, ${ }^{5}$ por ejemplo, en la descripción de sitios, de personajes y de incidencias. Los ojos encandilados de quien presencia una realidad que sobrepasa la imaginación ejercieron - parece probable - presión poderosa para engrandecerla, para magnificar las experiencias y para colorear su relato: no es lo mismo decir que Diego de Ordaz tenía una yegua —así, sin más-, que decir que era suya "una yegua rucia machorra, pasadera, y aunque corría poco” (Díaz [1632] 2011: 91). Pero en esa proclividad al adjetivo se apuntan, en principio, los valores literarios de su libro. Cortés y Bernal se deleitan en la descripción de sitios. El retrato que ambos hacen del tianguis de Tlatelolco, por ejemplo, da fe de ello. Ambos se solazan en el recuerdo y dan testimonio de la magnitud, de la riqueza, de la "policía” que imperaba allí (Díaz [1632] 2011: 330-331; Cortés 2009: 136-140). Y aunque la representación de ese mercado responde, en los dos casos, al asombro ante

5 Son varias las voces que lo califican como el narrador fundacional de América Hispánica. Carlos Fuentes (1990: 71), por ejemplo. 
lo insospechado, resultan obvias las diferencias (las cuales, por otra parte, bastarían para atribuir a cada escritor la autoría de su propia obra y no a Cortés la de ambas, aparte de otros detalles de mayor valía). La escritura del capitán obedece al esquema de la relación, esto es, al informe que se envía a la superioridad. Imposible que no se trasluzca en ella el pasmo (Cortés era consciente del tamaño de su hazaña y de la magnitud de su conquista), pero escribe movido por intereses políticos y aun por la necesidad de defenderse de los ataques de sus detractores. A diferencia de este, Bernal escribe para regodearse en el recuerdo - y en la exageración fantasiosa— ${ }^{6}$ y para quejarse un poco de su suerte. Conocedor de las cartas escritas por su jefe y también de la historia que este ordena escribir a Francisco López de Gómara, no muestra empacho en reproducir pasajes convividos con aquel y en calificarlos con sus propias sensaciones. Por ejemplo: "Digo que traían tantos dellos a vender aquella gran plaza como traen los portugueses los negros de Guinea [...] de la manera que hay en mi tierra, que es Medina del Campo, donde se hacen las ferias, que en cada calle están sus mercaderías por sí; ansí estaban en esta gran plaza..." (Díaz del Castillo 2011: 330-331). Esta y otras afirmaciones semejantes son expresiones más inclinadas a manifestar admiración que a redactar un reporte, con clara tendencia a la búsqueda retórica de la hipérbole.?

No bastan, sin embargo, las cualidades de una narración directa y emotiva para que Fernández de Pulgar permita la salida de su particular purgatorio de historiadores a Bernal. Lo salva, en cambio, la opinión que de él formula fray Juan de Torquemada: "A Bernal Díaz del Castillo le vindica el padre Torquemada en el Libro cuarto, capítulo IV de su Monarquía indiana, que dice: 'Yo conocí en la ciudad de Guatemala a Bernal Díaz del Castillo en su última vejez, y era hombre de todo crédito, etc."' ([1615] 1975: 14v).

\footnotetext{
Afirma que los comerciantes aztecas vendían pieles de tigre y de león; no existían en América antes de la Conquista.

7 En su sentido de "exageración o audacia... que consiste en subrayar lo que se dice al ponderarlo con la clara intención de trascender lo verosímil, es decir, de rebasar hasta lo increíble el 'verbum proprium'” (Beristáin 1985: s. v. Hipérbole).
} 
Lo ve, de todos modos, con menosprecio. Bernal justifica la escritura de su Historia por el propósito de repartir la gloria de la conquista del territorio más grande, más rico, más promisorio y menos imaginado por la España imperialista. No fue solo el capitán, dice, el artífice de la gloria. Los soldados, por igual cabos que rasos, merecen mención y reconocimiento. En términos generales, Hernán Cortés no menciona a sus colaboradores y eso encorajina a uno de ellos, Bernal, que, de paso, se siente mal remunerado, viejo, menospreciado, olvidado. Pero el reproche contraría a Fernández de Pulgar, que reclama en exclusiva la honra para Cortés, con una admiración que raya en veneración sin cortapisas. Aun aquellos detalles que Bernal menciona como al desgaire y que abonan para la configuración cabal del extremeño resultan soslayados en el manuscrito del cronista mayor de Indias si estos desvelan la faceta negativa del capitán. Así, verbigracia, el pasaje del escrito con carbón en la pared de la casa de Coyoacán, en el que se relata cómo cansados de esperar la parte del botín que consideraban suyo después del saqueo final de México Tenochtitlán, las huestes españolas, representadas por una voz anónima, se lamentan: “¡Oh qué triste está la ánima mea hasta que todo el oro que tiene tomado Cortés y escondido lo vea!" (Díaz [1632] 2011: 692); también la alusión suspicaz de la muerte de la Marcaida en extrañas condiciones: "también le pusieron [a Cortés] por delante la muerte de Catalina Juárez la Marcaida, su mujer" (Díaz [1632] 2011: 793). Un ejemplo más es el de la muerte en circunstancias por igual extrañas del licenciado Luis Ponce, encargado de fincar juicio de residencia a Cortés por la muerte de su mujer y por varias otras acusaciones: "Que luego que se comenzó a tomar la residencia quiso Nuestro Señor Jesucristo que por nuestros pecados y desdicha que cayó malo de modorra el licenciado Luis Ponce [...] Pues como fue muerto y enterrado [...] joír el murmurar que en México había de las personas que estaban mal con Cortés y con Sandoval! Que dijeron y afirmaron que le dieron ponzoña con que

8 La leyenda dice que se trataba de un dístico: "Tristis est anima mea / hasta que la parte vea”. La cita bíblica, parodiada en el muro de la casa de Cortés, de Mateo, 26: 38. 
murió, que ansí había hecho [Cortés] al Francisco de Garay” (Díaz [1632] 2011: 925-926).

Mucho más allá de la indulgencia, puesto que esta implicaría el reconocimiento de culpas en Cortés, y mucho más allá de la justificación de su conducta en atención - por ejemplo, a las circunstancias-, el encubrimiento de esta información por parte del cronista mayor obedece, sin duda, al propósito principal de su manuscrito: purificar de toda falta la imagen histórica de Cortés y, con ello, colaborar con su aportación en la justificación de la Conquista y del imperio católico español; sobre todo, si se considera que un propósito elemental del escrito de Fernández de Pulgar es el de disminuir los efectos de la leyenda negra, iniciada, según el propio riosecano, por fray Bartolomé de las Casas. ${ }^{9}$ En el ambiente cultural

9 Dice el manuscrito: :

quien mas ensagrento La pluma fue el Ob.po de chiapa d fr Bartolome de las casas, o Casau, en differentes escritos. copio algo de el, el R. P.e fr Fran.o Mazedo en el Propugnaculo. Lusitano gallico. imitale Hieronimo Benzon Milanes. q imprimio Bry lib2 de la aMerica, eyô el contrapunto un escritor, q saco el ano 1612 un libro intitulado: Recentes historias novi orbis. en otra imprefion se intitula, urbano Calveton, historia Latina, traducta es Benzone cum annotationibus a

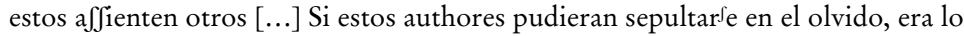
que merezian, pero como esto no es fazil; ya que andan en manos de muyos, vaya el veneno, con su antidoto, y aora, por lo general, pondre esta precauzion, Con Augusto Vischero, en su discurfo Historico Politico de la election de el Emperador, pag. 5. aun q los herejes dize, comunmente vozean, q el imperio hispanico en los indios, es injusto, por q el fin que tubieron los mas capitanes, y Legados, fue una insaziable avarizia, y no la enmienda, y converfion; sino la evafion, y destruction de estos amplissimos Reynos, y para esto se valen de el testimonio de B.me de las Cafas, Obp.o Espanol, en la Relazion de la destruction de la indias. Pero los Catholicos xpanos no ignoran, y las historias con continuada serie abundantemente testifican, q los Catholizissimos Reyes de España, nunca se dejaron, ni se dejan llebar, de el appetito de dominar, sino de procurar la Salud de las almas, no de la avarizia de el oro, como estilan los herejes, derribando tantos obispados, abbadias, monasterios, etc., q es una hambre execrable; sino de una codizia de sacar las almas de las gargantas de el demonio. no por appetito de gloria mundana, y transitoria; sino de la Eterna, y q ha de durar para siempre, no finalmente por vengarse de los indios; sino de el comun enemigo, q anda por todas partes, como leon, buscando a quien tragar, y todo esto perfezionô. y perfeziona felizissimamente el Moderno Catholizissimo Rey, ayudado de el auxilio y trabajo, de los P.pes de la compania de Jhs (y lo mismo puede dezir de otros Religiosos, de las demas ordenes, y ecctesiasticos seculares) q no perdonaron, ni perdonan, a su 
de España, en su balanza de poderes, en la crisis del siglo XVII, la apología resultaba urgente. Pero aun con respecto a Antonio de Solís la contribución de Fernández de Pulgar es, más bien, exigua. Carece, en comparación con aquel, de los recursos retóricos necesarios para dibujar a cabalidad la compleja personalidad del extremeño. Un ejemplo de ello es lo siguiente: cuando Fernández da cuenta de la actitud de Cortés ante la inminencia de la celada en la ciudad de Cholula (165r-v), aliada de los aztecas y enemiga de los de Tlaxcala, desperdicia la oportunidad de resaltar un aspecto determinante en sus éxitos militares: la astucia diplomática para doblegar el ánimo del enemigo y las virtudes de semiólogo que le permiten la lectura de los hechos sociales (Todorov 1989: 106-136).

En contraste, Solís saca provecho del relato de ese momento con maestría retórica. Los indicios implícitos de su personaje, las reticencias, la hipérbole y hasta el retruécano ("con reparar sin atender”) proponen un personaje sagaz, calculador aun en trances de desesperación al borde de la fatalidad. Estas son sus palabras:

Llamó Cortés a los embajadores de Motezuma, y con señas de intimidad, como quien les fiaba lo que no sabían, les dijo que había descubierto y averiguado una gran conjuración que le tenían armada los caciques y ciudadanos de Cholula [...] Y añadió que no solamente lo sabía por su propia especulación y vigilancia, pero se lo habían confesado ya los principales conjurados, disculpándose del trato doble con otra mayor culpa, pues se atrevían a decir que tenían orden y asistencias de Motezuma para deshacer alevosamente su ejército, lo cual ni era verosímil ni se podía creer semejante indignidad de un príncipe tan grande [...] Los embajadores procuraron fingir como pudieron que no sabían la conjuración, y trataron de salvar el crédito de su príncipe siguiendo el camino en que los puso Cortés con bajar el punto de su queja. No convenía entonces desconfiar a Motezuma ni hacer de un poderoso, resuelto a disimular,

propria sangre; sino q estubieron apparejados a derramarla por la salud de las almas, y lo estan, porq han convertido infinitas almas de Barbaros, a la verdadera, y vivifica fee, y por ella muchos han padezido martyrios, como lo testifican Las historias, y las Cartas, $\mathrm{q}$ han escrito muchos y se han publicado, y los que cada dia vienen de los Reynos de las indias etc. (16 r y $16 \mathrm{v})$. 
un enemigo poderoso descubierto; por cuya consideración se determinó [...] castigar la obra en sus instrumentos y contentándose con reparar el golpe sin atender al brazo ${ }^{10}$ (Solís [1684] 1970: 165).

No está exenta de cualidades la Historia verdadera de Pedro Fernández de Pulgar. La mayor de ellas, me parece, consiste en el juicio de las historias previas y en la confrontación de los escritos. Subyace a este examen una hipótesis histórica, por supuesto. De esa manera intenta pasar por el tamiz de su propia visión de la historia las apreciaciones de quienes la juzgaron con anterioridad, incluyendo, como queda dicho, a los propios protagonistas. Desde este punto de vista, Fernández de Pulgar representa una visión novedosa de la historia, cercana a la moderna. Lejos de reconstruir acontecimientos desde la memoria personal o de algún actor, emplea el procedimiento de acopiar - y, por desgracia, también de copiarinformación extraída de una seleccionada bibliografía. Sus autores preferidos (Cortés, Díaz del Castillo, Gómara) menudean en sus referencias por otra parte jamás señaladas con comillas y, si acaso, indicadas con un "esto Fulano”. Alguna lectura clerical, por ahí una transcripción de algún historiador antiguo, alguna cita que evidencia su cultura de bibliófilo. ${ }^{11}$

Pero el favorito por encima de todos es fray Juan de Torquemada. En la Monarquía indiana (1975) entra a saco y sin anuncio ni registro hurta tiradas desmedidas (es el caso, por mencionar el más notorio, de la copia textual que aparece del folio 327r al folio 370r; o sea, una copia de cuarenta y tres folios a dos caras, sin referencia). ${ }^{12}$

\footnotetext{
10 Modifico la puntuación.

11 "Su bibliofilia le llevó a crear dos magníficas bibliotecas que, reunidas y donadas por él a la Catedral de Palencia poco antes de su muerte, forman la que, no muy acrecentada, disfruta hoy el cabildo de aquella Santa Iglesia” (Cuesta 1951: 12).

12 Toma Fernández de Pulgar extractos a veces de muchas páginas, como puede verse en la relación que sigue, del volumen II, libro cuarto de la Monarquía indiana de fray Juan de Torquemada (a excepción de una cita expresa que procede del libro tercero). A esta obra corresponden las referencias, muy pocas veces citadas (consigno los casos en que aparece la referencia, así sea difusa), que se permite el cronista. Me ha simplificado en gran medida la labor de localización la edición digital que ha realizado el Instituto de Investigaciones Históricas de la Universidad Nacional Autónoma de México, consultable en la siguiente dirección: www.historicas.unam.mx/publicaciones/publicadigital/monarquia/
} 
Tratándose de un manuscrito que no llegó a las prensas, se impone la atenuante de que el autor pudo haber realizado enmiendas. En el documento, como está, se presenta como una larga copia, sobre todo en los capítulos finales.

\section{La circunstancia del manuscrito}

La Historia verdadera de Fernández de Pulgar es explicable por el ambiente en que se escribió, como cualquier texto. De su urdimbre es posible tirar a fin de identificar las circunstancias políticas, sociales, económicas en que se produce. A continuación, algunas reflexiones en torno a este tema.

Aun tratándose de un manuscrito, no deja de ser extraño que el de Fernández de Pulgar carezca de fecha. Tal falta podría verse justificada por la esperanza del autor de ver el texto en letras de imprenta, de modo que el impresor se encargara de esa tarea y consignara el pie editorial: ciudad, casa impresora y año. Como queda claro, no se produjo el acontecimiento, y el legajo de 382 pliegos a dos caras se conservó sin más datos que los que pueden inferirse de su contenido o de la biografía del autor. Del contenido poca

Es de advertir que hay extensas copias en que el autor introduce una decena de palabras propias. Aun así, el original es de Torquemada. Esta es la relación, en que presento el número de folio del manuscrito seguido de las páginas de la edición digital.

Folios: 34v (con cita), pp. 255-256; 171v (con cita), libro tercero, p. 416; 172r-73r (sin cita), pp. 144-146; 173r-173v (sin cita), pp. 146-147; 174r-175v (sin cita), pp. 148-150; 175r-176r (sin cita), pp. 150-51; 200v-205r (sin cita), pp. 168-173; 207v-209r (sin cita), pp. $173-175 ; 209 \mathrm{r}-211 \mathrm{r}$ (sin cita), pp. 173-179; 215r (con cita), pp. 179-180; 227v (sin cita), p. 273 ; 239r-240r (con cita), pp. 188-189; 248r-248v (con cita), p. 184; 248v (con cita), pp. $185-186 ; 275 \mathrm{r}$ (sin cita), p. $194 ; 257 \mathrm{v}-260 \mathrm{v}$ (sin cita), pp. 196-200; 262v-263r (sin cita), pp. 201-202; 276r bis-276v bis (sin cita), pp. 215-216; 279v-280r (con cita), pp. 214-215; 280r (con cita), p. 215; 280v (con cita), pp. 273-274; 284v (con cita), pp. 213-214; 285r (con cita), p. 217; 290r (sin cita), pp. 217-218; 291v (sin cita), p. 211; 292v-294v (sin cita), pp. 218-221; 295r-298v (sin cita), pp. 222-230; 301v (sin cita), p. 231; 310v-312v (sin cita), pp. $235-239 ; 313 \mathrm{r}$ (sin cita), p. 239; 313v-314v (sin cita), pp. $239-241 ; 315 \mathrm{r}-315 \mathrm{v}$ (sin cita), pp. 241-243; 316r-316v (sin cita), pp. 244-245; 323r-323v (sin cita), pp. 245-246; 324r$324 \mathrm{v}$ (sin cita), pp. 247-248; 327r-370r (sin cita), pp. 249-310; 370r (sin cita), p. 312; 370v (sin cita), p. 313; 373v (sin cita), p. 313; 375v-381v (con cita), pp. 320-327.

Quien coteje ambas obras, el manuscrito de Fernández de Pulgar con la Monarquía indiana, advertirá con facilidad el plagio. 
información que conduzca a la datación puede esperarse. Se centra en el recorrido de Hernán Cortés desde su estancia en Cuba hasta la capitulación de la ciudad de México Tenochtitlán; el procedimiento de narración es cronológico, como conviene a un relato histórico convencional, y no hay referencias que delaten el momento de la creación. Tampoco las virtualidades lingüísticas aportan mucha información. Aunque hay expresiones que determinan dialecto y norma, por ejemplo, resultaría poco técnico definir un período de la transformación del castellano con base en el empleo de alguna palabra o de alguna peculiaridad sintáctica. Por tanto, no hay más opción que recurrir a las noticias acerca de la vida del escritor, que tampoco son muchas. La única conjetura posible es que el volumen fue escrito en la segunda mitad del siglo XVII, a juzgar por la época en que el historiador ostentó el cargo de cronista mayor. No hay más pistas. Inclusive aquello que en una primera lectura genera expectativas se desvanece con rapidez. Así sucede con la mención de "don Pedro de Moctezuma, que aún vive" (277r). Claro: es una cita - declarada a medias - de la Historia de la conquista de México de Francisco López de Gómara. Pedro Tesifón de Moctezuma y de la Cueva, conde de Moctezuma por decreto de Felipe IV, había muerto en 1639. Pudo el autor tener noticia de él —el conde muere cuando Fernández cuenta con dieciocho años-, pero lo cierto es que no lo menciona por su cuenta, sino como parte de una cita sin referencia. La sola posibilidad de ubicar el texto, en suma, se deriva de la biografía del cronista.

Si la deducción no fuera descabellada (y si lo fuera, de todos modos, es la única posible), el entorno del infolio pertenece al reinado de Carlos II, el Hechizado. Se produce, por tanto, en el contexto de una España en crisis, simbolizada por la propia figura de un rey incapacitado en lo mental y en lo físico para ejercer el gobierno. A las graves dificultades sociales que distinguen los reinados de Felipe III y Felipe IV (abuelo y padre de Carlos II), habrían de sumarse momentos de incertidumbre en que el rey se convierte en figura de paja y la Corona pierde el control de España y de sus posesiones ultramarinas. Circunstancias en verdad poco favorables 
para el optimismo y para la fe en el futuro. Anulado el lazo que dotaba de coherencia al imperio hispánico, esto es, disminuido el poder hegemónico de un monarca a cuyo control se sometía toda decisión de importancia, como ocurría en los reinados de Carlos I y Felipe II, parecería que el imperio quedaba al garete con peligro inminente de naufragio, y que lo advertían las clases política y culta. Ante tal ausencia de dirección, se antojarían probables dos posturas: el examen riguroso de las circunstancias a fin de reconocer fallas y proponer remedios, o la vuelta de la mirada - un tanto evasivahacia atrás, con el propósito de lamentar que "todo tiempo pasado fue mejor" y de distinguir los mecanismos que propiciaron épocas heroicas. Sin suponer que estas dos actitudes son exclusivas entre sí, parecería que la Historia verdadera de Fernández de Pulgar se decanta por la propuesta de efectuar una revisión de los orígenes históricos del imperio, con objeto de reproducirlos y de recrearlos en su calidad de ejemplos, y depone cualquier actitud crítica de análisis y de proyecto; actitud conservadora, por otra parte, que, lejos de plantear la subversión histórica del concepto de nación y lejos de someter a juicio la gestión gubernativa del rey, se plantea la refundación de los muros de la patria, "si un tiempo fuertes, ya desmoronados”, sobre los cimientos de glorias pasadas.

Desde esa mirilla política (la que incide en el presente) e histórica (la que busca en el pasado), toca a Hernán Cortés convertirse en el emblema, en la piedra angular de la restauración. En la piedra angular y en la piedra de toque, en tanto que su imagen constituirá el catalizador para contrastar la valía (y, con ello, para tasarla también) del heroísmo español después de dos siglos de la gesta fundacional de la Nueva España. No faltaban modelos, desde luego. La historia española del siglo XVI cuenta con una multitud de personajes voluntariosos (héroes, stricto sensu) en los terrenos político, militar, religioso, artístico; pero a Fernández de Pulgar le resulta en particular atractiva la personalidad de Cortés y su aporte en la construcción de un imperio cuya extensión superaba la de todos los conocidos hasta ese momento. Las causas quedan apuntadas: su fe en una organización social en pirámide, desde la punta de la cual 
se giran directrices; la labor denodada y disciplinada en la edificación de esa estructura por parte de todos los agentes, desde el más encumbrado hasta el más obscuro, igual que en una colmena a cuyos integrantes mueve el instinto de conservar el grupo; la creencia en la imposición de pensamientos que se juzgan verdaderos - los dogmas religiosos son quizás los más trascendentes de ellos-; y la defensa de una moral, que no de una ética, que preconiza el derecho y la obligación que asisten al fuerte para ejercer tutela sobre el débil.

Por otro lado, controversial como es en sí misma, la figura histórica de Hernán Cortés exigía una revisión para validar la columna vertebral de la economía peninsular. Consecuencia de corruptelas como la venta de nombramientos civiles y eclesiásticos, de pésimas gestiones administrativas, del estancamiento científico y técnico, y aun de costumbres seculares como la negativa de nobles e hidalgos a ganarse la vida trabajando, las finanzas españolas (con la repercusión natural en la situación de las colonias) zozobraban. No habían desembocado en el desastre total merced a las pingües remesas que llegaban a la Corona desde el otro lado del Atlántico. Las ingentes cantidades de metales preciosos y de materias primas sostenían, así fuera con alfileres, la hacienda nacional pese a las equívocas administraciones de los Austrias y sus validos. En la producción de recursos americanos, suficiente apenas para mantener el inflado organismo burocrático en ambos lados del océano y la voracidad de boato de las cortes real y virreinales, se cifraba la garantía de una endeble estabilidad y, en buena medida, de la sobrevivencia pacífica. Sin posibilidades de variación, tal statu quo se preservaba en la Nueva España por el monopolio de las funciones administrativas en manos de peninsulares (con el disgusto de criollos y mestizos, como habría de verse andando el tiempo), pero exigía argumentos que la justificaran. La revalidación de la Conquista y de los derechos de usufructo que había generado, en su calidad de obra redentora de almas descarriadas, representaba una buena coartada. Vilipendiado y censurado, Hernán Cortés era una pieza inútil en esa estrategia; elevado a la altura de prócer, de generador de un nuevo estado, constituía el emblema de la pujanza española y reivindicaba la justicia del atraco. 
Por último, ya que no es la intención de estas líneas calar a fondo en los entresijos del siglo XVII, sino solo resaltar algunos aspectos que tocan de cerca y ayudan a explicar el manuscrito que aquí se juzga, sería necesario considerar también la función social del escritor en el período previo al nacimiento de los burgos - y de los burgueses-, llamados a convertirse en los motores económicos de una nueva disposición social, caducos el modelo medieval del feudo y el esquema renacentista de supremacía nobiliaria. En las particularidades de este último molde, el de la primacía de los nobles, germinan los rasgos distintivos de la Historia verdadera escrita por Pedro Fernández de Pulgar.

Superada la obligación primaria del escritor novel o poco (re)conocido, o sea, la de encauzar sus esfuerzos de creador a la mayor gloria de su benefactor, el título de cronista mayor aseguraba una cierta independencia. En el entendido de que el nombramiento se otorgaba tras una larga carrera, después de vencer muchas oposiciones y luego de mostrar adhesión institucional plena, la autonomía del historiador no representaba peligro ninguno para la monarquía ni para la Iglesia. Más aún, el cronista real se convertía en brazo armado — así fuera de péñola — del aparato de gobierno, en proclamador de dogmas y en difusor del discurso oficial. Los escritores contestatarios, los artistas opuestos al régimen, echaban mano de argucias para encubrir críticas y protestas (innumerables pasajes proporcionan la literatura y la pintura hispánicas del siglo XVII para ilustrar el recurso); disfrazaban el significado real con dobles sentidos, con elementos de disyunción referencial (Morin 1974: $127-130)^{13}$ o, de modo más tajante, se ocultaban en el anonimato o en el seudónimo. Unos, los institucionales, solían gozar de prebendas y de holgura económica; los otros, no.

\footnotetext{
13 Un ejemplo clásico del recurso de disyunción referencial en un texto del siglo XVII se encuentra en El buscón, en el pasaje que habla de los cardenales: "Por éstas y otras niñerías, estuvo preso; aunque, según a mí me han dicho después, salió de la cárcel con tanta honra, que le acompañaron doscientos cardenales, sino que a ninguno llamaban 'señoría”' (Quevedo [1626]1969: 71).
} 


\section{La retórica del manuscrito. Un apunte}

En el fondo de cualquier escrito existe una intención persuasiva, aunque, claro, pesa mucho más en un discurso político o en un sermón que en un poema lírico. De todos modos, aun en la comunicación en apariencia más trivial se intenta la imposición de ideas; es el ejercicio del poder en la comunicación cotidiana. El escrito de Fernández de Pulgar se cubre con una apariencia de reconstrucción de acontecimientos, pero se propone, sobre todo, aleccionar en materia de religión, de moral y de política. La recapitulación histórica en su obra adquiere sentido en razón de la interpretación de los hechos y a efecto de valorarlos desde la perspectiva de sus consecuencias. Rehúye, no obstante, la disquisición filosófica con respecto a temas embarazosos como, por ejemplo, la legitimidad de la Conquista. En la disyuntiva - acaso representada paradigmáticamente por Francisco de Vitoria y Juan Ginés de Sepúlveda- del posible contraste de ideas en ejercicio de dialéctica civilizada a fin de llegar a la verdad, o de la imposición de dogmas por las buenas o por las malas, Fernández se inclina sin más por la segunda opción. Pontifica, así, acerca de derechos y obligaciones naturales; el señor rige y el siervo acata o el capitán ordena y el soldado ejecuta, como queda dicho. Lo hace también con respecto a conceptos religiosos (en el cristianismo está la verdad; no en otras creencias), en relación con la organización política de las comunidades (por ello, jamás cuestiona el régimen monárquico de la cultura azteca), en torno a valores éticos (es pecado inmolar seres humanos como ofrenda para dioses; no lo es cuando el fin consiste en acrecentar la creencia en uno solo, cuando el homicidio se realiza ad maiorem Dei gloriam). En una escala de valores que concuerda por completo con la de la Iglesia posterior al Concilio de Trento, Fernández de Pulgar escribe su texto con el propósito básico de adoctrinar, emparejando de este modo el objetivo final de la narración histórica con la práctica del púlpito; después de todo, ambos, sermón y relato (en el de ficción no hay ni por qué pensar) parecerían proceder de un común origen, el del entrenamiento en la palestra: 
La virtus más general del discurso se halla contenida en el adverbio bene dicere, y el fin más general del discurso consiste en persuadere. También la narratio, naturalmente, tiene que tener esta virtus y servir a este objetivo. Dentro del fin general de persuadere hay que considerar como fin específico de la narratio el docere... y el movere. Pero el docere es imprescindible y nuclear... y a él sirven las tres virtutes necesarias... dentro de las cuales el delectare y movere desempeñan una función auxiliar (Lausberg, 1975: 266).

Obvio parecerá a quien lea las páginas del escrito de Fernández que no se ha propuesto delectare a sus lectores. Enseñarles, persuadirlos y moverlos (docere, persuadere et movere eos), sí. Enseñarles la verdad histórica de la gesta fundacional de la Nueva España, convencerlos de los beneficios que produjo a la humanidad como cruzada catequética y de la potencia de la religión católica y de la casta hispana, y alentarlos - moverlos- a la defensa de la fe y del imperio en momentos que se vislumbraban aciagos. Por ello, hasta gestos y actos dignos de censura desde la perspectiva del teólogo inflexible que se agazapa atrás de comentarios y apostillas aparecen atenuados, se soslayan o se justifican mediante la esgrima retórica de la explicación o en atención a la conquista de un bien que - con sofismas por argumentos- se presuponen supremos con razonamientos de premisa mayor adulterada. Esto es: sobre la base sin pruebas de que la doctrina católica es la verdadera, de que la salvación del ser humano depende de su conocimiento, de que es obligación de todo cristiano divulgar su convicción, el autor de esta Historia verdadera valida la imposición de una cultura sobre otra a la que se aniquila, y la práctica de la violencia para llegar a tal fin. Nada nuevo, en realidad. Fernández de Pulgar encarna las ideas de su clase en su tiempo. Pero parece preciso consignar estos recursos y esta visión a modo de muy apretado compendio de su concepción del discurso histórico-literario y de su finalidad docente. En el propósito de enseñar, de desvelar hechos y revelar su verdad -la considera universal y en eso se equivoca, es solo su verdad-, estriba su punto de vista de la estética. El deleite (delectare), según esa apreciación, se vuelve complemento y resultado del 
conocimiento (docere), de manera que la belleza (de nuevo, según esa visión) no radica en la organización de los componentes de un discurso (función poética) ni menos aún en el deleite producido a los sentidos (como en las artes no poéticas), sino en la obtención de saberes y en el hallazgo de la verdad.

Subsumidos en ese proyecto, otros procedimientos palidecen. A la distancia de dos siglos, los hechos que se cuentan en esta Historia verdadera pertenecen al dominio generalizado de los letrados; en realidad, al material de Fernández le queda vetado el impacto de la auténtica revelación. Después de las Relaciones (s/f S. XVI) de Cortés, de la Historia de López de Gómara (1552), de la Historia verdadera de Bernal (probablemente 1568) y de otras obras escritas por protagonistas (los Comentarios reales del Inca Garcilaso y los Comentarios de Álvar Núñez, por ejemplo), a las posteriores crónicas de la Conquista no les quedaba más remedio que adoptar un papel antifónico y, si acaso, interpretativo o valorativo; inclusive trabajos tan inmediatos de los sucesos como la Monarquía indiana, en la parte que corresponde a la llegada y presencia de los conquistadores, tienen que recurrir a las fuentes originales y reiterar la narración. Absorbidos por la finalidad didáctica, los recursos estilísticos, las estrategias de presentación narrativa, las figuras del narrador, el planteamiento de la temporalidad — que con otros constituyen la dispositio clásica- - y hasta las tácticas de presentación del discurso que modifican la forma y dan testimonio de un uso poético del lenguaje quedan preteridos y subordinados a un fin magisterial. Como queda apuntado líneas arriba, la Historia verdadera de Bernal -que menciono en este punto puesto que significa la referencia paradigmática de la que aquí se presenta- es muy superior en ese aspecto. Díaz del Castillo no intenta practicar el magisterio, por descontado que se propone persuadir, pero desea, quizás con más ahínco, participar de una memoria, compartir recuerdos y maravillar (delectare) a sus lectores con la remembranza. Este fin, el de provocar admiración, aunado a su intuición de relator-novelista, lo obliga por necesidad a echar mano de argucias que le garanticen la atención creciente de sus lectores. Es muy amplio su bagaje de 
medios narrativos: la descripción detallada de lugares, la relación de acontecimientos (en especial, los de carácter bélico), la reticencia irónica con respecto a hechos que le inconforman y, muy en particular, el bosquejo de personajes, a quienes representa con indicios explícitos e implícitos tanto en sus procederes como en su aspecto (canon renacentista). Baste recordar, como ejemplo, el acabado retrato del tlatoani Moctezuma (por no hablar del de Hernán Cortés). Dedica a la composición del personaje el capítulo XCI (Díaz [1632] 2011: 321-329); Fernández, una veintena de líneas (179r). Pero, al margen de la extensión - que no deja de ser significativa por aquello de que ex abundantia cordis os loquitur-, se distinguen con claridad dos proyectos de literatura. En Bernal el boceto es poliédrico, en tanto que toca múltiples aspectos de la apariencia y, en particular, de la conducta y de las costumbres de Moctezuma. Su dibujo, por otra parte, además de su colorido narrativo, esboza un personaje complejo y polifacético, de modo que nos plantea la contradictoriedad, la humana sutileza del monarca augusto y del hombre pusilánime, espantado por el misterio de lo ignoto y de los meandros del sino. Así adquiere vigor, por contraste, como paradoja, el pasaje en que ese mismo personaje a quien nadie se atreve a mirar cara a cara sea lapidado por una mano anónima, firma colectiva de la desaprobación. ${ }^{14}$ Acaso, en efecto, la descripción que elabora el soldado se aleja de las costumbres de la época. ${ }^{15} \mathrm{Tal}$ vez el alejamiento es deliberado: impactado por la presencia de un personaje al que los conquistadores subyugan en el terreno militar y bélico, Bernal, paradójicamente, no puede evitar mirarlo hacia arriba (de rodillas él, de pie el personaje, como en las epopeyas griegas) y lo describe bajo los principios de un canon personal, guiado por su instinto narrativo. De todas maneras, el canon de descripción física al que parece adherirse Díaz del Castillo concede igual importancia a lo

14 Gesta similar a la de Fuente Ovejuna, cuatro décadas antes de que naciera Lope.

15 Serés opina que tal "semblanza... no se ajusta a las convenciones del género, pues pasa de una cosa a otra por asociación, concomitancia o contigüidad; por ejemplo, de la limpieza corporal a la moral, apuntando de paso, por concomitancia, sus costumbres sexuales y hábitos vestimentarios” (2011: 321). 
físico que a lo moral: es renacentista. En ese aspecto, el esquema que traza Fernández de Pulgar corresponde a modelos anteriores.

Como era de esperarse de acuerdo con su actitud magisterial, en los proemios de la Historia verdadera de Pedro Fernández de Pulgar se concentra la intención de su relato. El proemio es el sitio natural del exordio, que a su vez "es el comienzo del discurso. El objetivo del exordio es ganarse la simpatía del juez (o, en sentido más amplio, del público) hacia el asunto del discurso, defendido parcialmente" (Lausberg 1975: 240). A la manera de los tribunos, Fernández de Pulgar expone desde un principio el punto en controversia que quiere ventilar y la solución por la que opta. Su postura, eso sí, es clara y honesta. Aquí, por ejemplo:

escribo en este libro La Conquista de Mexico. grande emprefa, y dignissima de La memoria de toda La posteridad. y q mereze dezirse con toda verdad, assi porq depende de ella El dominio Justo. q tienen los catholicos Reyes de la nueva España. Como por la gloria de el Conquistador fernando Cortes. resplandezieron en este heroe La prudenzia. y el valor. y aunq comunm.te donde ay mas prudenzia, y valor, suele andar escafa la fortuna. en cortes andubo liberal La fortuna, y quiso competir con su valor, y prudenzia. o digamos, que le gobernaba con espezialidad La divina providenzia inspirandole, tan peculiarmente Las actiones, q ni las podra prevenir prudenzia humana, ni el mayor valor emprenderlas y menos perfezionarlas. ni de la buena fortuna se podian esperar. (177r)

Seguido de explicaciones, de argumentaciones, de amplificaciones, ${ }^{16}$ el planteamiento general de los exordios propone de entrada una postura con respecto a una controversia. El discurso de esta laya pertenece más bien al ámbito del pleito jurídico o de la discusión forense que al de la reconstrucción histórica o del relato literario; sin embargo, posee la cualidad de transparentar desde el

16 Lausberg: "Al exordium sigue ahora la participación (parcial) a los jueces del estado de la causa (que hay que demostrar en la argumentatio) ... Esta comunicación se llama

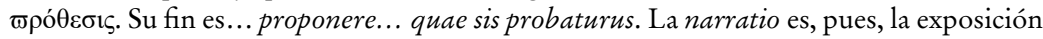
detallada, parcial, encarecedora, de lo que de manera ceñida y escueta se expresa en la propositio" (1975: 260-261). 
inicio la finalidad de una disquisición. En este caso, según confesión de parte, la demostración de "el dominio justo que tienen los católicos reyes de la Nueva España”, "la gloria del conquistador Fernando Cortés" y la manifiesta intervención de "la divina providencia inspirándole tan peculiarmente las acciones, que ni las podía prevenir prudencia humana, ni el mayor valor emprenderlas y menos perfeccionarlas, ni de la buena fortuna se podían esperar”. En suma, el aspecto retórico de la Historia verdadera de Fernández de Pulgar guarda relación más estrecha con el debate forense que con la disposición estética o con el empleo de la lengua poética.

\section{La práctica de la imitación y de la copia}

Cobró prestigio en el Renacimiento. La emulación de modelos prestigiosos constituía un reto que muchos escritores asumieron, y son célebres algunos casos. Sor Juana, por ejemplo, era imitadora contumaz. Su Primero sueño pudo y debió haberse llamado, sin más, El sueño (Alfonso Méndez Plancarte evitó publicarlo con el ordinal en su edición de la Biblioteca del Estudiante Universitario de la UNAM); la intención de numerarlo — atribuible a sus primeros editores, puesto que ella refiere, en su Respuesta al obispo Fernández de Santa Cruz, que "no me acuerdo haber escrito por mi gusto sino es un papelillo que llaman El sueño" (Sor Juana 1976: 471) - se debía a la esperanza de que la jerónima escribiera otros y a que se advertían como modelo las Soledades gongorinas. Otro tanto, el título de su drama Los empeños de una casa, que guarda un voluntario parecido con el título de la obra de Calderón, Los empeños de un acaso. Y más muestras en la obra de sor Juana, que alguna vez inclusive se pasa de tueste y copia a plenitud. La imitación era, sin embargo, un modo de tributo. Se imitaba a los escritores consagrados, a quienes se trataba de emular o de superar. Son conocidos los intentos exitosos, además del de sor Juana imitando a Góngora: Boscán imitando a los poetas italianos y aun a algún catalán como Ausiàs March, Matías de Bocanegra imitando a Calderón, Juan de Palafox y Mendoza imitando a San Juan; pero 
con seguridad los fracasos habrán sido mucho más numerosos. Los poetas cuya imitación constituía un desafío y cuya emulación garantizaba un apreciable galardón (Góngora, Quevedo, Calderón, Lope, sor Juana misma y, de modo muy especial, los clásicos griegos y latinos) personificaban también una piedra de toque rigurosa que dejaba al descubierto el metal de que estaba hecha la lengua poética que los remedaba. Solía ser, por ello, un envite para poetas prominentes:

Por ese motivo, la imitación no solo era juzgada como actividad propia de ingenios reducidos, sino que, por el contrario, se creía reservada a los auténticos poetas de calidad —aquellos que osaban imitar a los universalmente reconocidos porque se consideraban aptos para ello-, al grado de que el Brocense llegó a considerar "que no (se) tiene por buen poeta al que no imita a los excelentes antiguos" (Valencia 2005: 15).

Aunque se practicó de modo sistemático durante el Renacimiento $^{17}$ y la costumbre de la imitación-emulación perduró por siglos, "en los albores del romanticismo alemán" decayó (Alatorre 2003: 35). Cobró valor, entonces, la originalidad. Y aun en las ocasiones en que un poeta o un prosista se inspiraba en los procedimientos de otro, desvelaba su modelo y presentaba su trabajo como un "homenaje a...":

No es que los poetas de estos dos siglos [XIX y XX] se hayan abstenido ya de imitar a los anteriores a ellos, pero lo hacen, por así decir, al margen de su quehacer verdadero, como simples pasatiempos, y cuando los imprimen suelen hacerlo al final de todo, como en apéndice: "Traducido de Catulo", "Imitación de John Donne", "A la manera de Mallarmé" (Alatorre 2003: 35).

\footnotetext{
17 "La doctrina sobre la imitación (mimesis) en la Poética de Aristóteles, redescubierta y celebrada por los humanistas italianos, es bastante compleja, pero el uso acabó por recortarla y simplificarla, de manera que imitación vino a significar la adopción de ideas e imágenes de los poetas 'clásicos' (los consagrados). Así, por ejemplo, el mérito número uno de Virgilio era haber 'imitado' en su Eneida a Homero” (Alatorre 2003: 35).
} 
En lo que respecta a las crónicas de la Conquista, la imitación y, más que ella, la reiteración resultaba inevitable. Como queda dicho arriba, la originalidad en la relación de descubrimientos y de conquistas era potestad casi exclusiva de los protagonistas. Los epígonos tenían que documentarse en sus testimonios y extraer de ellos información y aun apreciaciones de carácter emotivo, pues parece difícil que alguien ayuno de experiencia propia, alguien que no haya visto personajes, sitios o hechos, alguien que no haya presenciado la gesta del descubrimiento y la conquista fuera capaz de interpretar el impacto sensorial y psicológico con intensidad sino a través de la mirada del actor. Hubo, por ello, a fin de no asumir el papel de seguidor o discípulo, quien prefirió transitar por otras vertientes de la historia, reconstruir la gesta desde el punto de vista de los perdedores (desde la visión de los vencidos), como fray Bernardino (Sahagún 1989: 717-809), o emprender el camino de la configuración conceptual de un nuevo mundo, maravilloso también en su aspecto natural, como Gonzalo Fernández de Oviedo (Gerbi 1978: 310-363).

Resulta fácil comprender el deseo de emular a escritores acreditados. Por más compleja que sea la "doctrina sobre la imitación” - y sí lo es-, su procedimiento tiene un principio no tan complicado, sin embargo. Pretende reproducir esquemas, tropos (metáforas y metonimias, sobre todo), temas y, en suma, estrategias propias del lenguaje artístico. Pero sobra decir que en esa práctica el modelo sirve de base de una creación en que habrán de imponerse la invención y la marca del retador. Lo contrario daría como resultado la copia, plagio o reproducción, según la intención de quien reproduce. No obstante que la idea de plagio parece haberse afirmado después del romanticismo, existe en la naturaleza de los escritos la exigencia básica de una cierta originalidad. Esto es: lo menos que se puede pedir a un escritor es que sea capaz de hablar con sus propias palabras. Aun en el caso de la escritura científica, tan precisada de préstamos y de citas, la diferencia entre la copia y la erudición puede ser, a veces, el uso de comillas. Pero también en el ámbito de la escritura científica, con legitimidad puede exigir un lector que existan, al menos, visos de novedad. Novedad en el enfoque, en 
el uso de fuentes, en la emisión de juicios de valor y, como mínimo requerimiento, en el pensamiento propio.

La Historia verdadera de la conquista de la Nueva España de Pedro Fernández de Pulgar reproduce, sin pizca de variación, fragmentos - enormes en ocasiones- de sus fuentes. La Monarquía indiana de fray Juan de Torquemada se lleva la palma. Fernández la convierte en su botín y le birla grandes parrafadas. ${ }^{18}$ No lo hace así con ningún otro texto. Ni con las Cartas de Cortés ni con la Historia de Bernal, a pesar de su valor de testimonio original, y eso parece significativo. A Cortés no lo copia porque su escrito pretende erigirse en pedestal del marqués del Valle y absurdo resultaría copiar las palabras del homenajeado, porque los documentos cortesianos son más conocidos que otros (la Monarquía de Torquemada y la Historia natural y moral de Acosta, por ejemplo) y porque él mismo les reconoce carácter de alegato reivindicativo. A Díaz del Castillo tampoco lo copia, aunque por razones diferentes. Bernal, inclusive leído en la versión alterada que publicó fray Francisco Remón, representa su antípoda, un punto de vista opuesto, en tanto que exige el reconocimiento de méritos para sí y para el resto de las huestes españolas, y la aceptación de que la empresa gigantesca de la dominación fue obra colectiva. A ellos dos no los copia, pero a otros los reproduce palabra por palabra o con ligeras variaciones, y se cuida muy poco de indicarlo, ${ }^{19}$ de modo que su Historia parece obra tramada con hilvanes que unen, según su decisión, partes más o menos extensas de textos consagrados, en particular, aquellos que apuntalan el enfoque crítico que pretende defender. De acuerdo con las convenciones de la época, declara — solo a veces- que emplea palabras ajenas; usa para ese fin la fórmula "esto fulano", aunque deje al lector la tarea de distinguir o de adivinar los límites de la cita.

\footnotetext{
18 Parrafadas o páginas, según queda apuntado en la nota 12 de este trabajo.

19 Cuesta (1951) se equivoca: "Pero si la mayor parte de los manuscritos son originales del cronista, no puede afirmarse otro tanto con el contenido de ellos, pues utiliza la obra ajena abundantemente, aunque con la honradez de citar siempre la procedencia” (16). Las citas de la procedencia se reducen a la expresión "esto", seguido del nombre del autor de las palabras que transcribe. Sin embargo, no acostumbra el uso de comillas. Ni siquiera indica siempre el uso de palabras ajenas.
} 
No es despreciable el trabajo, a pesar de lo anterior. Dos atenuantes lo amparan e impiden tachar algunas de sus partes, de plano, como plagio. El primero: se trata de un manuscrito que no llegó a publicarse, es decir, algo así como un pecado que no llegó a cometerse o un crimen que no se perpetró. Los preparativos para la imprenta habrían forzado al autor a una revisión concienzuda y quizás a la depuración de los "préstamos". El segundo (creo que de mucho más peso): inclinado por la función docente de la narración por encima de la recreativa, como he dicho antes, el autor hace uso de recursos que le permitan allegarse elementos de construcción de una hipótesis ("el dominio justo que tienen los católicos reyes de la Nueva España”, "la gloria del conquistador Fernando Cortés" y la manifiesta intervención de la divina providencia) y que a su vez operen como argumentos probatorios de sus asertos. Esta estrategia, aunada a una flaca capacidad creativa, le permite ejercer de dómine, ya que no de creador.

\section{Coda}

Resguardado por la Biblioteca Nacional de España en su sede madrileña de Recoletos, el material sobre el que aquí se diserta es un manuscrito de 382 folios escritos a dos caras. No es posible saber si su autor manuscribió algunas páginas, pero sí que son varios los amanuenses (al menos tres, uno de los cuales probablemente es el novohispano Carlos de Sigüenza y Góngora [Cuesta 1951: 16]). De la lectura detenida de este infolio es posible inferir que se propone dos fines preponderantes:

(1) Persuadir a sus lectores acerca de la legítima conquista y posesión de los reyes de España sobre territorios americanos ("el dominio justo que tienen los católicos reyes de la Nueva España”), lo cual explica, además, la disposición retórica de su escrito a manera de reconstrucción histórica y de discurso forense, alternadamente. Con ello, de acuerdo con los postulados de la retórica clásica, 
se propone convencer, conmover y mover a acciones consecuentes, de manera particular en momentos de frágil gestión administrativa de los territorios coloniales.

(2) Para lograr ese fin, Pedro Fernández de Pulgar se impone la tarea de socavar el valor histórico de la obra de Bernal Díaz del Castillo, cuya actitud crítica con respecto a Hernán Cortés significa, aparte de una insubordinación bajo el punto de vista del cronista mayor, una descalificación de la figura histórica del capitán, y Cortés, desde su misma perspectiva, constituye el pilar del esquema político del espíritu conquistador y de la institución monárquica.

La Historia verdadera de la conquista de la Nueva España de Pedro Fernández de Pulgar, a pesar de las claras inclinaciones conservadoras del autor (aspecto que automáticamente resta objetividad a su crónica), posee un alto valor en la historia de la historiografía y en la historia de la literatura. En cuanto a la historia de la historiografía, constituye un ejemplo de los procedimientos científico-históricos distintivos del siglo XVII, puesto que transparenta los recursos de que se vale para llegar al conocimiento y para lograr la reconstrucción del pasado; esto es, el proceso de acumulación documental y el del contraste de los documentos, pese a que - como ya se ha dicho- tal contraste se realice mediante el balanceo de pesos específicos; esto es: unos documentos valen más que otros, por no hablar de los que quedan soslayados en absoluto (la crónica indígena recopilada por fray Bernardino de Sahagún, por ejemplo). En el aspecto histórico de la literatura, la obra de Fernández de Pulgar representa también un prototipo; ejemplifica el lapso en que la crónica — como relación de hechos sociales que se organiza bajo un esquema temporal canónico, a diferencia de la novela- adquiere valor de palestra para la difusión de saberes y para el examen del transcurso comunitario; falta mucho para que se presente en escena la crónica periodística y el análisis sociológico, pero son escritos de la naturaleza de esta Historia los que plantan los cimientos de aquellos, así sea para enmendar sus estrategias. 


\section{Referencias bibliográficas}

Alatorre, Antonio

2003 El sueño erótico en la poesía española de los siglos de oro. México: Fondo de Cultura Económica.

BERISTÁIN, Helena

1985 Diccionario de retórica y poética. México: UNAM.

BlecuA, José Manuel

1984 Poesía de la edad de oro, tomo II. Barroco. Madrid: Castalia.

CorTÉs, Hernán

2009 Cartas de relación. Madrid: Dastin.

s/f Relaciones de Hernán Cortés al Emperador Carlos V. Manuscrito.

CRUZ, Sor Juana Inés de la

1976 “Respuesta a Sor Filotea”. En Obras completas, tomo. IV. México D.F.: Fondo de Cultura Económica.

Cuesta, Luisa

1951 “Introducción de Pedro Fernández del Pulgar”. En Tropheos gloriosos de los reyes catbolicos de España. Madrid: Biblioteca Nacional de Madrid, 9-22.

DíAz del CASTILlo, Bernal

[1632] 2011 Historia verdadera de la conquista de la Nueva España. Madrid: RAE.

Duverger, Christian

2015 Crónica de la eternidad. ¿Quién escribió la Historia verdadera de la conquista de la Nueva España? México: Penguin Random House.

Fernández de Pulgar, Pedro

s/f Historia verdadera de la conquista de la Nueva España. Manuscrito.

Fuentes, Carlos

$1990 \quad$ Valiente mundo nuevo. Madrid, Mondadori España.

Gerbi, Antonello

1978 La naturaleza de las Indias nuevas. México: Fondo de Cultura Económica. 
2002 Inventario general de manuscritos de la Biblioteca Nacional. Madrid: Biblioteca Nacional de España.

Laín Entralgo, Pedro

1956 La generación del noventa y ocho. Madrid: Espasa-Calpe.

LAUSBERG, Heinrich

1975 Manual de retórica literaria. Madrid: Gredos.

LÓPEZ DE GÓMARA, Francisco

1979 Historia de la conquista de México. Caracas: Ayacucho.

Morin, Violette

1974 "El chiste". Análisis estructural del relato. Buenos Aires: Tiempo Contemporáneo, 121-145.

NúÑez CabeZa de Vaca, Álvar

1971 [1542] Naufragios y comentarios. Madrid: Espasa-Calpe.

PAZ, Julián

1992 Catálogo de manuscritos de América existentes en la Biblioteca Nacional. Madrid: Biblioteca Nacional de España.

Quevedo, Francisco de

[1626] 1969 Vida del Buscón don Pablos. México: Porrúa.

SAHAGÚN, Bernardino de

1989 Historia general de las cosas de Nueva España. México: Porrúa.

SERÉs, Guillermo

2011 "Edición, estudio y notas". Historia verdadera de la conquista de la Nueva España. Madrid: RAE, 1117-1457.

Solís, Antonio

1843 Historia de la conquista de Méjico, ed. de José de la Revilla. Madrid, Gabinete Literario.

Solís, Antonio de

[1684] 1970 Historia de la conquista de Méjico. Madrid: Espasa-Calpe.

Todorov, Tzvetan

1989 La conquista de América. El problema del otro. México: Siglo XXI.

TORquemada, Juan de

[1615] 1975 Monarquía indiana. México: UNAM. Consultado: 8 de setiembre de 2015. http://www.historicas.unam.mx/ publicaciones/catalogo/ficha?id=154 
502 Lexis Vol. XLII (2) 2018

VALENCIA, Henoc

2005 Ecos y repercusiones de la Canción a la vista de un desengaño. Tesis correspondiente al grado de doctor. Ciudad de México: Universidad Nacional Autónoma de México.

VeGA, Inca Garcilaso de la

[1609] 2008 Comentarios reales de los incas. Lima: Editores Importadores.

Recepción: 28/06/2017

Aceptación: 4/05/2018 